\title{
Referrals to hospital by general practitioners: a study of compliance and communication
}

\author{
Kieran J McGlade, Terry Bradley, Gerard J J Murphy, Gerard P P Lundy
}

\begin{abstract}
To determine the extent of non-attendance at first hospital appointments 269 hospital referrals made in one practice over 14 weeks were analysed retrospectively. Non-attendance was more likely among patients referred to outpatient departments than to casualty or for admission. Fifteen per cent (41/269) of all patients and 20\% (33/167) of outpatients failed to keep their initial appointments. Prolonged waiting times from referral to appointment were significantly related to non-attendance. Twenty weeks after the last referral had been made no communication had been received by the practice for $24 \%(61 / 252)$ of all referral letters received by the hospital.
\end{abstract}

Minimum delays to appointments and improved communication between hospitals and general practitioners would help general practitioners to make appropriate referrals and improve compliance.

\section{Introduction}

The referral system, in many ways a cornerstone of the National Health Service, has increasingly come under scrutiny from the profession and government alike. Previous work has concentrated on the reasons for the well recognised but ill understood variation in referral rates among individual general practitioners, ${ }^{1.3}$ and some work has investigated the communication aspects of the referral process, ${ }^{4}$ but few studies have examined non-compliance of patients in general practice referred to hospital.

Most general practitioners are familiar with the frustrating experience of receiving notification of patients' failure to keep their hospital appointments, and requests by defaulting patients for another referral are not uncommon. We determined the extent of nonattendance at first hospital appointments, explored some of the reasons for non-attendance, and examined whether or not timely communications had been received from the hospital and what form these replies took.

Department of General

Practice, Queen's

University, Belfast

BT7 1NN

Kieran J McGlade, MRCGP, senior registrar

Stewartstown Road Health Centre, Dunmurry, Belfast Terry Bradley, MRCGP, general practitioner

Gerard J J Murphy, MRCGP, general practitioner

Gerard P P Lundy, MRCGP, general practitioner

Correspondence to: $\operatorname{Dr} \mathrm{K} \mathrm{J}$ McGlade, Dunluce Health Centre, Belfast BT9 7HR. other is filed for audit. The audit copies were used for a retrospective analysis of referrals made over 14 weeks in the summer of 1987; the analysis was carried out as shown in the flow chart (figure).
Method

The practice is situated in west Belfast, an area of high unemployment and socioeconomic deprivation. Three full time principals and a senior registrar/tutor in general practice from the department of general practice, Queen's University of Belfast, served 4822 patients. The practice uses a fixed heading referral form with two attached carbonless copies. ${ }^{5}$ The original is given to the patient for posting, one of the
All referrals made by the practice doctors (in the surgery, during house calls, or during out of hours calls) were included in the study. Referrals to antenatal clinics were not included as these were usually made with a different type of referral form. Domiciliary consultations and patients whose notes were no longer available were also excluded. Data recorded for each patient included sex; date of birth; general practitioner making the referral; date of referral; whether the referral was for a normal, early, or immediate appointment; details of the hospitals, consultants, and specialties; and whether the request was for admission or for attendance at the outpatient or casualty departments. In addition it was noted whether or not the hospital had received the referral letter and whether the patient had attended, was admitted, or did not attend. Communications from the hospitals were classified as handwritten note only, letter only, note and letter, "did not attend" slip, or no correspondence received. A record was kept of dates of correspondence, dates communications had been received by the practice, and the date of the appointment or admission (when the exact date of the appointment could not be ascertained directly the date on the reply letter from the hospital was used). The audit was carried out 20 weeks after the last referral to be monitored had been made.

The data were analysed with the statistical package for the social sciences (SPSSX). Age on date of referral, delay between referral and appointment, and delay

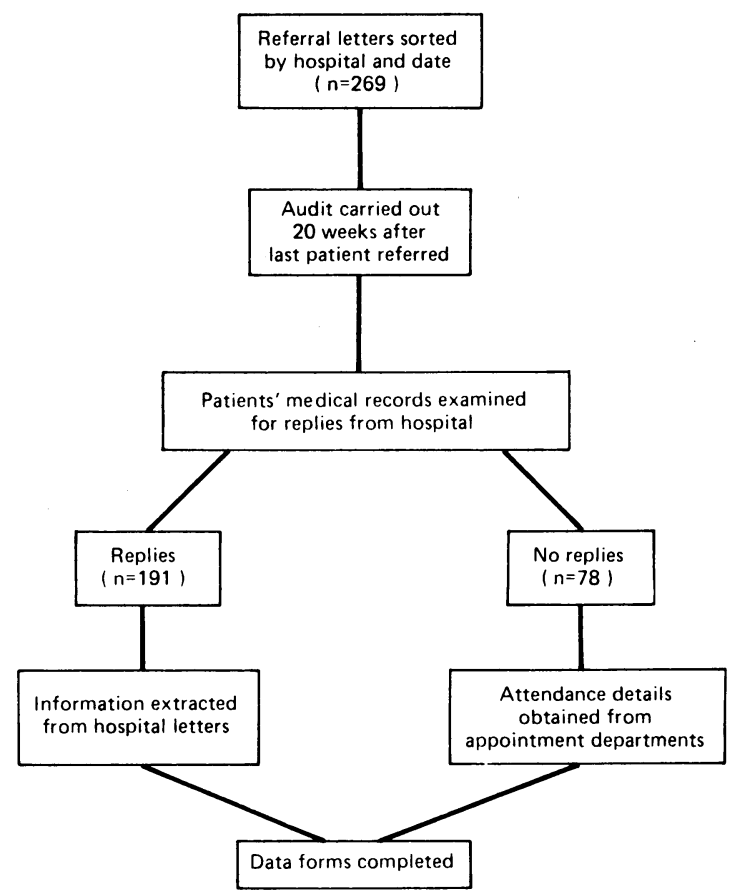

Analysis of referrals from general practice to hospital 
between appointment and receipt of communication by the practice were calculated directly. Numbers were compared with the $\chi^{2}$ test. In all comparisons the level of significance was taken as $\mathbf{p}<0 \cdot 05$.

\section{Results}

The practice referred 280 patients to hospital during the study period of 14 weeks. This represented $8 \%$ of all doctor-patient contacts and was comparable to the mean referral rate of $6.6 \%$ found by Wilkin and Smith. ${ }^{2}$ Eleven referrals were excluded from the analysis: notes were no longer available for five, three had never been on the practice list, two charts could not be traced, and one paediatric cardiology referral had a waiting time of nine months to appointment, which meant that the relevant information was not available at the time of the analysis.

Of the 269 patients admitted to the study, 101 were men and 168 women, a ratio of $1: 1 \cdot 7$ compared with a ratio in the practice population of $1: 1 \cdot 2$. Table I shows the number of all patients referred to various specialties who did not attend, the number of outpatients who did not attend, and the time to outpatient appointments in each specialty. Table II shows the number of patients in each referral category (outpatients, accidents or emergencies, or for admission) who did not attend for their appointments. Forty one patients $(15 \%)$ were not seen by the hospitals, and $17(6 \%)$ referral letters had not been received.

Appointment dates were available for 154 of the 167 referrals to outpatient departments. Only seven of the 105 patients whose appointment date was two months or less after referral did not keep their appointment, but significantly more patients ( 14 of 49) whose appointment took longer than two months to get did not keep their appointment $\left(\chi^{2}=11 \cdot 82, \mathrm{df}=1\right.$, $\mathrm{p}=0.001)$. The median waiting time for an outpatient appointment was 36 days for those attending and 86 days for those defaulting. Age, sex, general practitioner making the referral, degree of urgency stated in the referral letter, and whether a consultant was named were not related to whether patients attended.

By the end of the study the hospital had communicated with the practice about 191 of the 269 referrals, sending a "did not attend" slip in eight cases, a handwritten note in 23, a typed letter in 121 , and both a note and a letter in 39 . No communication was received in 78 cases (in 17 of these the referral letter had not been received by the hospital). Thus by the end of the study no replies had been received to 61 of the 252 letters that had reached the hospital (24\%). Replies took an average of 17 days (range 2-55) from the appointment date to reach the practice.

TABLE I-Referrals to hospital by specialty. Time to appointment given for outpatients only

\begin{tabular}{|c|c|c|c|c|c|c|}
\hline & \multicolumn{2}{|c|}{ All referrals } & \multicolumn{4}{|c|}{ Outpatients } \\
\hline & \multirow[b]{2}{*}{ Total } & \multirow{2}{*}{$\begin{array}{l}\text { No }(\%) \text { of } \\
\text { patients not } \\
\text { attending }\end{array}$} & \multirow[b]{2}{*}{ Total } & \multirow{2}{*}{$\begin{array}{c}\text { No }(\%) \text { of } \\
\text { patients } \\
\text { not attending }\end{array}$} & \multicolumn{2}{|c|}{$\begin{array}{l}\text { Median time to appointment } \\
\text { (days) }(\text { range })^{\star}\end{array}$} \\
\hline & & & & & Not attending & Attending \\
\hline Medicine & 61 & $7(11)$ & 38 & $5(13)$ & $36(13-53)$ & $34(1-155)$ \\
\hline Surgery & 46 & $5(11)$ & 30 & $5(17)$ & $110(15-133)$ & $25(5-98)$ \\
\hline Accident and emergency & 43 & $5(12)$ & & & & \\
\hline Gynaecology & 35 & $4(11)$ & 25 & $3(12)$ & $119(83-145)$ & $21(1-76)$ \\
\hline Dermatology & 23 & $4(17)$ & 21 & $4(19)$ & $27(19-61)$ & $19(2-46)$ \\
\hline Ear, nose, and throat & 23 & $9(39)$ & 22 & $9(41)$ & $134(105-145)$ & $75(1-165)$ \\
\hline Ophthalmology & 11 & $2(18)$ & 11 & $2(18)$ & $82(75-89)$ & $71(16-86)$ \\
\hline Infectious diseases & 7 & 0 & & & & \\
\hline Psychiatry & 5 & $2(40)$ & 5 & $2(40)$ & $79(73-86)$ & $100(18-119)$ \\
\hline Other & 15 & $3(20)$ & 15 & $3(20)$ & $136(98-150)$ & $70(1-141)$ \\
\hline $\begin{array}{l}\text { Total } \\
\text { Mean (range) waiting time }\end{array}$ & 269 & $41(15)$ & 167 & $33(20)$ & $86(13-150)$ & $36(1-165)$ \\
\hline
\end{tabular}

^Data for 154 patients
TABLE II -Numbers (percentages) of patients referred to hospital attending and not attending first appointment. Categories were stated on referral letter

\begin{tabular}{lcc}
\hline & Attending & Not attending \\
\hline Outpatients & $134(80)$ & $33(20)$ \\
Casualty & $38(88)$ & $5(12)$ \\
Requests for admission & $56(95)$ & $3(5)$ \\
\hline Total & $228(85)$ & $41^{\star}(15)$
\end{tabular}

$\chi^{2}=7 \cdot 8, \mathrm{df}=2, \mathrm{p}=0.02$

${ }^{\star}$ Includes 17 letters not received by the hospital.

The appointment dates of referrals that had a reply were not significantly further from the end of the study than those that did not.

\section{Discussion}

The figure of almost $20 \%$ non-attendance for first outpatient appointments may seem high. Grace and Armstrong, however, reported a 9\% non-attendance at hospital outpatient departments, and Carpenter et al reported a $31.4 \%$ non-attendance for first psychiatric outpatient appointments. ${ }^{67}$ In a study of 16 outpatient clinics held by five consultants non-attendance rates as high as $30 \%$ were recorded, and in a study of prescribing up to $20 \%$ of prescriptions were not redeemed. ${ }^{89}$ Perhaps other management options - for example, advice and reassurance-are also subject to such non-compliance.

Seventeen of the 41 non-attendances were accounted for by the non-receipt of letters by the hospital. Some of these letters might have gone astray and others were not posted by the patient. If the practice were to post all referral letters compliance would not necessarily be improved. Indeed, giving the patient the letter to post preserves patient autonomy and gives patients an active role in referral.

Our study shows that prolonged waiting times are a major factor in non-attendance at outpatient departments in all specialties except psychiatry. This may be because of improvement of symptoms or forgetfulness about distant appointments. Comparisons of the specialties should be treated with some caution because of the small numbers in each. Other variables must, however, exert an influence among specialties; we can only speculate what these may be. For example, the $19 \%$ non-attendance for appointments in dermatology, for which the median waiting time was only 27 days, might have been due to some inappropriate referrals by the practice, the relevant conditions having spontaneously resolved. Referrals in ophthalmology have a similar non-attendance rate despite having much longer waiting times than in dermatology. This might reflect patients' greater concern about eye conditions than skin conditions. Referrals to ear, nose, and throat departments showed the greatest non-attendance rate $(41 \%)$ and had a median waiting time for patients who did not attend nearly twice that of those who did attend. Other studies have also found high rates of non-attendance at ear, nose, and throat departments and have proposed that the self limiting nature of many ear, nose, and throat symptoms is an important factor. ${ }^{810}$ More general reasons for defaulting include fear or mistrust of hospitals; fear of serious illness being found; adequate reassurance obtained from the general practitioner; socioeconomic factors, such as transport difficulties; and perception of the referral as unnecessary.

A disturbing finding was that no communication whatsoever was received for about one quarter of all referrals and only eight did not attend slips were received by the practice. Inevitably management of a number of these patients will be compromised. The 
extent of these communication difficulties and the impact of non-compliance raise questions about medicolegal responsibility and underline the pivotal role of the general practitioner in the continuing care of patients. Patients often have queries arising from visits to hospital that can be difficult for general practitioners to answer if they are unaware of what went on in the hospital.

The lack of replies in general could not be accounted for by appointment dates occurring close to the end of the study. It would therefore seem unwise to consider referral as an event that results in the complete transfer of clinical responsibility. Rather, it should be regarded as a complex process which frequently breaks down.

How might this state of affairs be improved? Grace and Armstrong suggested that to gain full compliance and to maximise the effect of any course of action or treatment the patient should be aware of the reasoning behind that action and should have taken part in arriving at the decision. ${ }^{11}$ Awareness of the extent of non-compliance should also prompt the general practitioner to evaluate each referral decision fully. Similarly, delays to appointment should be kept to a minimum. Appointment reminders for those patients who have long waiting times may be useful. Prompt notification by the hospital of appointments not kept, coupled with systematic audit in the practice, would enable the general practitioner to follow up defaulters efficiently. Notifying the general practitioner as well as the patient of hospital appointments through internal mail facilities (and ultimately through electronic mail) would speed things up and would help general practitioners to make appropriate referrals. Adequate clerical and secretarial staffing in the hospital are a vital element in the communication process.

The variables that we found to be significant can be generalised only to referrals from our practice. If confirmed in other studies these findings have important implications for general practitioners and hospitals in terms of resources and management of patients. Serious flaws exist in the communication process, and means must be sought to overcome them if patient care is not to suffer.

We thank the Claire Wand Fund of the BMA for financial assistance.

1 Dowie R. The refertal process and general medicine outpatient system. First report: a statistical analysis. Canterbury: Health Services Research Unit, University of Kent, 1980.

2 Wilkin D, Smith AG. Variation in general practitioners' referral rates to consultants. IR Coll Gen Pract 1987;37:350-3.

3 Wilkin D, Smith AG. Explaining variation in general practitioner referrals to hospital. Fam Pract 1987; 4:160-8.

4 Sandler DA, Mitchell JRA. Interim discharge summaries: how are they best delivered to general practitioners? BrMed f 1987;295:1523-5.

5 Murphy GJJ, McGlade KJ, Lundy GPP, Bradley T. Towards better medical records. Update 1988:36:2092-5.

6 Grace JF, Armstrong D. Referral to hospital: perceptions of patients, general practitioners and consultants about necessity and suitability of referral. Fam Pract 1987;4:170-5

7 Carpenter PJ, Morrow GR, Del Gaudio AC, Ritzler BA. Who keeps the first outpatient appointment? Am F Psychiatry 1981;138:102-5.

8 Davies P. Why don't patients turn up? Health and Social Service fournal $1984 ; 94: 886-7$

9 Rashid A. Do patients cash prescriptions? Br Med F 1982;284:24-6.

10 Leese AM, Wilson JA, Murray JAM. A survey of the non-attendance rate at the ENT clinic of a district general hospital. Clin Otolaryngol 1986;11:37-40.

11 Grace JF, Armstrong D. Reasons for referral to hospital: extent of agreement between the perceptions of patients, general practitioners and consultants. Fam Pract 1986;3:143-7.

(Accepted 13 September 1988)

\section{BOOKS RECEIVED}

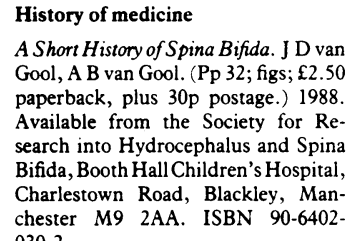
$030-2$.

\section{Laser therapy}

Low Level Laser Therapy: a Practical Introduction. T Ohshiro, R G CalIntroduction. T Ohshiro, R G Cal-
derhead. (Pp 160; figs; $£ 30.50$.) Chiderhead. (Pp 160; figs; $£ 30.50$.) Chi-
chester: Wiley, 1988. ISBN 0-47191956-X.

\section{Medical education}

A Revision Text in Medical Physiology. O A Sofola. ( $\mathrm{Pp} 96$; figs; £7.50 paperback.) 1988. Available from Professo O A Sofola, School of Basic Medical Sciences, College of Medicine of the University of Lagos, PMB 12003 , Lagos, Nigeria. ISBN 978-2752-01-0.

\section{Medical ethics}

Life and Death Decision Making. B A Brody. (Pp 272; £22.50.) New York Oxford University Press, 1988. ISBN 0-19-505007-X.

Nutrition

World Review of Nutrition and Dietetics. Vol 56. "Aspects of Nutritional Physiology." Volume and series edito G H Bourne: (Pp 272; figs; £101.90.) Basel: Karger, 1988. Distributed by John Wiley and Sons. ISBN 3-8055. 4785-4.

\section{Obstetrics and gynaecology}

The Menopause. J W W Studd, M Whitehead. (Pp 320; figs; $£ 49.50$. Oxford: Blackwell Scientific, 1988. ISBN 0-632-01815-1.
Oncology

Cervical Smear Test: What Every Woman Should Know. A Singer, Szarewski. (Pp 144; figs; £5.99 paperback.) London: Macdonald Optima, 1988. ISBN 0-356-15065-8.

\section{Orthopaedics}

Orthopaedic Biomaterials in Research and Practice. J Black. (Pp 408; fig $£ 35$ paperback.) New York: Churchill Livingstone, 1988. ISBN 0-44308485-8.

\section{Paediatrics}

Overcoming Common Problems. "Coping Successfully with Your Child's Skin Problems." P Carson. (Pp 128; Skin Problems." P Carson. (Pp 128; £.95 paperback.) London: Sheld
Press, 1988. ISBN 0-85969-569-7.

Paediatric Clinical Examination. D Gill, N O'Brien. (Pp 208; figs; 25.95 paperback.) Edinburgh: Churchill Livingstone, 1988. ISBN 0-44303956-9.

Perspectives in Pediatric Pathology. Vol 12. "Cardiovascular Diseases." Volume and series editors H S Rosenberg, J Bernstein. (Pp 172; figs; £90.) Basel: Karger, 1988. Distributed by John Wiley. ISBN 3-8055-4716-1.

\section{Paramedical}

Occupational Therapy in Mental Health Principles in Practice. Ed D W Scott, $\mathrm{N}$ Katz. (Pp 232; £30 hardback, £15 paperback.) London: Taylor and Francis, 1988. ISBN hardback 0-85066-464-0, paperback 0-85066$451-9$.

\section{Prostaglandins}

Prostaglandins, Leukotrienes, and Cancer. "Eicosanoids and Radiation." Ed P Polgar. Series editors K V Honn, L J Marnett. (Pp 196; figs; £39.50.) Boston: Kluwer, 1988. ISBN 0-89838$361-7$

\section{Psychiatry}

Gaskell Psychiatry Series. "Consent and the Incompetent Patient: Ethics, Law, and Medicine." [Meeting, London, December 1986.] Ed S R Hirsch, J Harris. (Pp 112; $£ 7.50$ paperback.) London: Royal College of Psychiatrists, 1988. ISBN 0-902241-22-2.

Progress in Psychiatry. "The Psychobiology of Bulimia." [Based on a Symposium, Washington DC, May 1986.] posium, Washington DC, May 1986.] Ed J I Hudson, H G Pope, Jr. Series
editor D Spiegel. (Pp 272; figs; £15.) editor D Spiegel. (Pp 272; figs; £15.)
Washington DC: American PsyWashington DC: American Psy-
chiatric Society, 1987. Distributed by chiatric Society, 1987. Distributed by Cambridge Uni

\section{Psychology}

The Child's World of Illness: the Development of Health and Illness Behaviour. S R Wilkinson. (Pp 304; $£ 30$. Cambridge: Cambridge University Press, 1988. ISBN 0-521-32873-X.

Psychology in Action: Working with Children and Their Families. M
Herbert. (Pp 240; 44.95 paperback.) Herbert. (Pp 240; $£ 4.95$ paperback.)
Leicester: The British Psychological Leicester: The British Psychological
Society, 1988, in association with Society, 1988, in association with 80-8.

Schizophrenia: an Integrated Approach to Research and Treatment. M J Birchto Research and Treatment. M J Birchwood, S E Hallett, $M$ C Preston. (Pp 416; 112.95 paperback.) London:
Longman, 1988. ISBN 0-58229607-2.

\section{Radiology}

Series in Radiology. "X-Ray Differential Diagnosis in Small Bowel Disease. A Practical Approach." J L Sellink. (Pp 192; figs; £54.90.) Dordrecht: Kluwer, 1988. ISBN 0-89838-351-X.

\section{Surgery}

Developments in Surgery. "Progress in Surgery of the Liver, Pancreas and
Biliary System." Ed S Bengmark. (Pp 448; figs; £76.) Dordrecht: Niihof 1988. Distributed by MTP Press. ISBN 0-89838-956-9.

\section{Urology}

Practical Urological Endoscopy. T B Hargreave. (Pp 256; figs; £39.50. Oxford: Blackwell Scientific Public Oxford: Blackwell Scientific Public

\section{Miscellaneous}

Bibliography on Regional Variations in Health Care. No 2: 1987. (Pp 28; paperback, price not stated.) Copenpaperback, price not stated.) CopenRegional Office for Europe, 1988.

The Care and Feeding of Ideas: a Guide to Encouraging Creativity. J L Adams. Pp 224; figs; £6.95 paperback.) Harmondsworth: Penguin, 1988. ISBN 0 14-010592-1.

Clinical Trial Procedure-Notes for Doctors. A J Munro. (Pp 80; paperback, price not stated.) Association fo Clinical Research, 11 Uxbridge Street, London W8 7TQ.

Continuing the Education of Health Workers: a Workshop Manual. F Abbatt, A Mejia. (Pp 200; \$21 paperback. Geneva: World Helth Organisation, 1988. ISBN 92-4-154220-9.

Coping with Multiple Sclerosis. C Benz. (Pp 160; £5.99 paperback.) London: Macdonald Optima, 1988. ISBN 0-356-12793-1.

A Dictionary of Speech Therapy. DW Morris. (Pp 200; £12 paperback. London: Taylor and Francis, 1988. London: Taylor and

Easy Does It! A Guide to Exercise and Healthcare for the Over 50s. L. Hilton (Pp 144; figs; $\$ 4.99$ paperback.) London: Macdonald Optima, 1988. ISBN 0-356-17524-3.

Families with a Difference: Varieties of Surrogate Parenthood. M Humphrey, Surrogate Parenthood. M Humphrey, back, £9.95 paperback. London

Routledge, 1988. ISBN hardback 0-415-00689-9, paperback 0-41500690-2.

A Fate Worse Than Debt. S George. (Pp 304;£4.99 paperback.) Harmondsworth: Penguin, 1988. ISBN 0-14022789-X.

The Good Health Handbook. P Mansfield. (Pp 332; 17.95 paperback.) London: Grafton Books, 1988. ISBN 0-246-13169-1.

Harrap's Dictionary of Medicine and Health. Harrap. (Pp 482; £8.95.) London: Harrap, 1988. ISBN 0-24554609-X.

The Miracle Nutrient: Coenzyme Q10. E G Bliznakov, G L Hunt. (Pp 240; \{3.50 paperback.) Wellingborough: Thorsons, 1988. ISBN 0-7225-1715-7.

A Passion for Science. L Wolpert, A Richards. (Pp 216; figs; £15.) Oxford: Richards. (Pp 216, figs; L15.) Oxford: Oxford Univer

Perfecting the World: the Life and Times of Dr Thomas Hodgkin 1798-1866. A M Kass, E H Kass. (Pp 670; figs; \$34.95.) Boston: Harcourt Brace Jovanovich, 1988. ISBN 0-15-171700-1. 